\title{
Reproductive Issues of Women with Epilepsy
}

Sanjeev V. Thomas

Sree Chitra Tirunal Institute for Medical Sciences and Technology

Trivandrum, India.

\begin{abstract}
There are about 10 million people with epilepsy in India and a quarter of them are women in reproductive age group. The social stigma of epilepsy has pervasive impact on the life of people with epilepsy particularly women. The cyclical hormonal changes during menstrual cycle and during pregnancy can influence the seizure pattern in women with epilepsy. Exposure to antiepileptic drugs (AEDs) can increase the risk of fetal malformations in the infants. This risk is higher with polytherapy and valproate in higher doses. A small proportion of children with antenatal AED exposure can have problems with cognitive development. All women with epilepsy need to have preconception evaluation to simplify the treatment of epilepsy. It is preferable to avoid valproate as an AED antiepileptic drug in women who are planning pregnancy.
\end{abstract}

Keywords : Epilepsy, pregnancy, antiepileptic drugs, fetal malformation, infertility, cognition.

Correspondence : Dr. Sanjeev V. Thomas, Professor of Neurology and Head of RMN centre for comprehensive epilepsy care, Department of Neurology, Sree Chitra Tirunal Institute for Medical Sciences and Technology, Trivandrum-695011, India. Phone 0471 2524468,Email: sanjeev.v.thomas@gmail.com.

BALDEV SINGH ORATION delivered during NAMSCON 2016 at the All India Institute of Medical Sciences, Raipur. 


\section{INTRODUCTION}

Epilepsy is a disease known to humanity from time immemorial. The earliest documentation of epilepsy is in the Babylonian text on Medicine, Sakikku which was written before BC 1000 . These stone tablets are saved in the British Museum at London. They have described epilepsy as Miqtu as a collection of what we today label as generalized tonic clonic seizures, absences, drop attacks and focal seizures with or without loss of awareness. They had even described the Jacksonian march of focal motor seizures and seizures characterized by myrthless laughter (gelastic seizures) (1). It was five hundred year later (BC 500) that Hippocrates had broken the myth of supernatural causation of epilepsy. In his text book he has described epilepsy as a disorder of the brain (2). Indian system of medicine had documented epilepsy in detail as early as 6 - 2nd century BC. Indian physicians interpreted epilepsy (apasmara) as a disorder of brain that leads to disturbance in memory or consciousness. Similarly there are detailed description of epilepsy in prehistoric literature from central and south America (3) and Africa (4).

\section{Burden of epilepsy :}

Epilepsy is one of the most common serious neurological disorders in the world. It is estimated that there are about 70 million people with epilepsy in the world. There are several studies on prevalence of epilepsy from different parts of India. However there is much variation in the definition, survey methodology, level of ascertainment etc. A meta analysis of several epidemiological studies from different parts of India had shown that the corrected prevalence of active epilepsy per 1000 population was 5.59 with $95 \%$ confidence interval ranging from 4.15 to 7.03 . Prevalence was higher in rural areas and among men when compared to urban areas and women (5). A recent meta analysis has shown that the median incidence of epilepsy was 50.4 per 100,000 population per year (Inter quartile range was $33.6-75.7=6$ ). The incidence in low income countries was higher 81.7 (IQR 28-239.5) when compared to high income countries 45.0 (IQR 30.5 - 66.7). This includes one study from India (6) by Late Prof. K.S. Mani, the father of Indian modern epileptology.

Globally it accounts for 17 million disability adjusted life years (DALY) lost which amounts to $1 \%$ of all DALY. More than $90 \%$ of these are reported from low and middle income countries. Epilepsy causes a major economic burden to the country. The cost of epilepsy from a nations perspective consists of Direct cost related to Medical expenditures, hospital services, home care services and ancillary services. Another component of direct cost is the cost of the care provided by the family and friends, cost of transportation and housekeeping. The second component of the cost is the Indirect cost related to loss of productivity and earnings by way of absence from gainful employment, income lost by family members etc. A third dimension to the cost 
of a disease is the Intangible cost attributed to the pain, suffering and social stigma which is often not taken in to consideration while computing the cost of an illness. We carried out a multi centric study of the cost of epilepsy in India which is the yard stick that WHO often use for the developing world (7). Although the cost of epilepsy in terms of dollars may be low because of the low monetary value of Indian Rupees, it constituted more than $80 \%$ of the per capita GNP at that time. More than $70 \%$ of the cost of epilepsy was due to indirect component which could be reduced substantially by improving the direct services for diagnosis and treatment of epilepsy. It appears that it is a wise economic decision to invest more on the treatment of epilepsy in order as it is likely to yield considerable savings from lower indirect cost.

\section{Women and epilepsy :}

Epilepsy affects men and women in equal proportions. Yet women experience the consequences of epilepsy more than men. The social stigma of epilepsy has more profound effect on women (8). It was observed that the stigma has several levels. On an individual level it leads to lower self esteem, withdrawal, self imposed isolation and a tendency to internalize shame. On a social level it influences social variables such as social integration, social networking and peer group activities. Lastly on a community level it leads to difficulties in arranging marriage or secure a job. In a survey carried out in Kerala state, $31 \%$ and $27 \%$ thought epilepsy was a hereditary disorder and a form of insanity, respectively. About $40 \%$ of the respondents felt that individuals with epilepsy could not be properly educated or employed (9). As a result women have more difficulty in finding a life partner and getting a job. In a direct comparison of men and women matched for age and type of epilepsy it was observed that comorbidities, lower employment and higher anxiety state were more frequent for WWE compared to MWE. Females had more difficulty in finding life partners compared to males. Women with epilepsy (WWE) were at increased risk of divorce (10). The treatment gap is wider for women than for men with epilepsy (11). This gap is even wider when the women live in villages.

\section{Infertility :}

On biological terms epilepsy can lead to a variety of medical situations. A survey that compared WWE attending to a tertiary care centre in south India with the women in general in the Kerala state the former had more abortions, smaller family size and greater proportion of women with no living child (12). A subsequent prospective study had confirmed that WWE enrolled in the Kerala Registry of Epilepsy and Pregnancy had higher risk of infertility $(38.4 \%)$ compared to age matched women in Kerala State $(15 \%)$. Their family size (0.6) was one third that of women in general (1.87). The risk of infertility increased as the number of AEDs were increased (13). In a follow up study it was also observed that in this registry women with infertility had 
abnormal hormonal profile when compared to women who had pregnancy (14). This was characterized by higher testosterone level abnormal LH/FSH ratio and lower progesterone levels in the blood which mimic the anovulatory ovarian cycles and PCOS. In a recent study at our Institute we had observed that $24 \%$ of WWE fulfilled the ATP III criteria for Metabolic Syndrome (15).

\section{Epilepsy and Pregnancy :}

Pregnancy can modify the epilepsy in a large proportion of women. Progesterone, the predominant hormone in pregnancy has favourable effects that reduce the seizure frequency as it has antiepileptic properties. In contrast the blood level of several antiepileptic drugs, particularly lamotrigine, oxcarbazepine and levetiracetam are likely to drop considerably in the second and third trimester of pregnancy as their clearance is increased several folds. Data from the KREP indicates that of the 1,297 pregnancies in WWE with complete seizure data, $47.8 \%$ were seizure free during pregnancy. Some $15 \%$ of women may experience seizure aggravation during pregnancy. Seizure relapse was highest during the three peripartum days. Women with partial seizures or on polytherapy had higher risk of relapse (16).

A variety of complications of pregnancy appear to be increased in WWE such as spontaneous abortion, pregnancy induced hypertension, antepartum or post partum haemorrhage, caesarean section and preterm labour (17). Data from the

Table 1. Comparison of the epilepsy and pregnancy registries

\begin{tabular}{|l|l|l|l|l|l|}
\hline Country & UK & US & KREP* & EUROPE \# & Australia \\
\hline year & 1996 & 1997 & 1998 & 1999 & 2000 \\
\hline $\begin{array}{l}\text { Preconception } \\
\text { cases }\end{array}$ & No & No & Yes & No & No \\
\hline $\begin{array}{l}\text { Women not on } \\
\text { AEDs }\end{array}$ & Yes & No & Yes & No & Yes \\
\hline Exclusion & $\begin{array}{l}\text { AED } \\
\text { change }\end{array}$ & & & $\begin{array}{l}\text { AED } \\
\text { change }\end{array}$ & \\
\hline Data collection & 2 contacts & 3 contacts & 4 contacts & 4 contacts & 4 (phone) \\
\hline $\begin{array}{l}\text { Outcome } \\
\text { ascertained at }\end{array}$ & $<12$ wks & $<12$ wks & $\begin{array}{l}12 \text { months } \\
12 \text { years }\end{array}$ & 12 months & 12 months \\
\hline $\begin{array}{l}\text { Control } \\
\text { Internal }\end{array}$ & $\begin{array}{l}\text { External } \\
\text { Non } \\
\text { epilepsy }\end{array}$ & $\begin{array}{l}\text { External } \\
\& \\
\text { Internal }\end{array}$ & Internal & $\begin{array}{l}\text { Internal\& } \\
\text { External }\end{array}$ \\
\hline $\begin{array}{l}\text { * Kerala Registry of Epilepsy and Pregnancy } \\
\text { \# European registry of antiepileptic drugs and pregnancy which also has data coming } \\
\text { from south and central America, Japan, Kerala and Australia. }\end{array}$ \\
\hline
\end{tabular}


KREP point towards increased risk of spontaneous abortion, gestational hypertension, pre-eclampsia and anemia in WWE when compared to healthy women (18).

The malformation risk of antenatal exposure to antiepileptic drug exposure was first noticed in the 1960s. Since then it had been observed that most AEDs carried increased risk of fetal malformation. Systematic prospective collection of data on the malformation risk for pregnancies in WWE were began with the pregnancy registry in UK in 1996 . This was followed by setting up of registry in the North America (1997), Kerala (1998), Europe (1999) and Australia (2000). Most of registries enrol WWE during the first trimester of pregnancy and complete the data collection by 3 rd or 12 th post partum month. The Kerala Registry of Epilepsy and Pregnancy is unique in enrolling women in the preconception stage or in first trimester and following up their children till the age of 18 years (Table 1 ).

The overall major malformation rate in the UK registry for all AED exposed cases was $4.2 \%$ (95\% confidence interval (CI), $3.6 \%$ to $5.0 \%$ ). The rates in the Kerala registry was $7.1 \%(95 \% \mathrm{CI}$ 5.98 - 8.44). The risk of MCM with polytherapy is significantly higher than that of monotherapy. Among the monotherapy exposures those exposed to Valproate had significantly higher risk of MCM. Recent studies have shown that the malformation risk increased as the dose of AEDs increased, particularly for valproate, levetiracetam, lamotrigine, cabrbamazepine and phenobarbitone (19). The commonly reported malformations are given in table 2 .

Table 2. Commonly encountered malformations in children with antenatal exposure to antiepileptic drugs

\begin{tabular}{|ll|}
\hline Cardiac & \\
& Atrial septal defect \\
& Ventricular Septal defect \\
& Patent Ductus Arteriosus \\
& Tetrology of Fallot \\
& Double outlet ventrible \\
\hline Nervous system & Meningo myelocoele \\
& Spina bifida \\
& Neural tube defect \\
& Microcephaly \\
\hline Skeletal & Cleft lip \\
& Cleft palate \\
& Tallipes equinovarus \\
\hline Renal & Agenesis of kidney \\
& Hydronephrosis \\
& Pelviureteric junction obstruction \\
& Posterior Urethral valve \\
& Hyposadias \\
\hline GIT & Omphalocoele \\
& Cyst in Liver \\
\hline
\end{tabular}




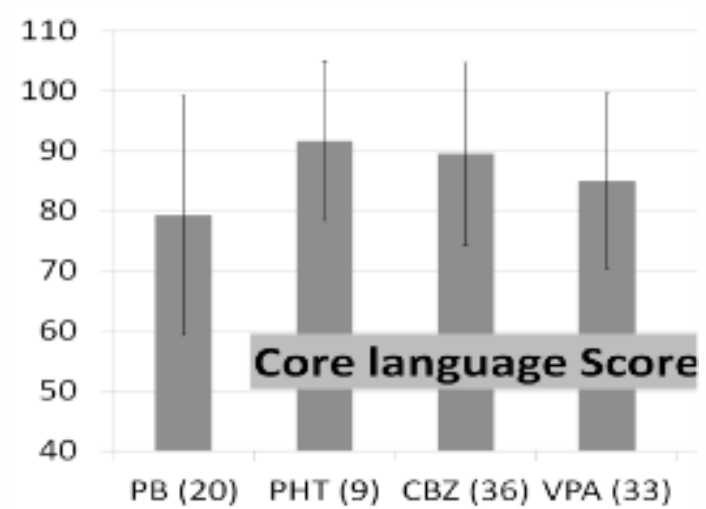

Fig. 1 : Bar chart showing the mean score with standard deviation for the language functions on children with antenatal exposure to different antiepileptic drugs as monotherapy. $(\mathrm{PB}=$ Phenobarbitone; $\mathrm{PHT}=\mathrm{Phenytoin}$; $\mathrm{CBZ}=$ Carbamazepine; $\mathrm{VPA}=$ valproate)

The malformation risk of sodium valproate is significantly higher than that of other AEDs according to the data from all the pregnancy registries. As a result it is now recommended not to use valproate as the first drug of choice in newly diagnosed epilepsy in girls and women with childbearing potential.

\section{Cognitive developmental issues of children with antenatal exposure to AEDs :}

The negative impact of antenatal exposure to AEDs on the cognitive development of children had been the focus of research in the recent past. The KREP had been prospectively following up a large cohort of such children from birth till adolescence. The setting of the pregnancy registry enabled us to acquire data on the maternal characteristics, AED usage during pregnancy, complications of pregnancy and neonatal status in a prospective manner. Evaluation of these children at one year of age had shown that there is increased risk of motor or mental developmental delay in children with prenatal AED exposure. The risk was higher for those with polytherapy or valproate therapy (20). Further follow up of this cohort at six years showed that they had significantly lower IQ and language performance when compared to school children without antenatal AED exposure (21). This cohort continued to show impairment in IQ, visual reproduction and frontal lobe function when evaluated between $10-12$ years of age (22). The language functions of children with antenatal exposure to Phenobarbitone was significantly lower than that of children with exposure to carbamazepine or low dose valproate (Fig. 1).

A retrospective analysis of children aged 5 - 9 years with prenatal exposure to levetiracetam, topiramate or valproate monotherapy showed that those exposed to higher doses of valproate had 
lower performance on several yardsticks of cognitive function when compared to other AEDs (23). Data from the NEAD study (Neurodevelopmental Effects of Antiepileptic Drugs study) have also confirmed that children with AED exposure, particularly those exposed to high dose valproate had significantly lower IQ when evaluated at one year, three years $(24,25)$ and six years of age (26). Another retrospective study had shown that those exposed to valproate as mono or polytherapy had higher risk of additional educational needs at school when compared to those exposed to carbamazepine (27). These data have given a clear signal that antenatal exposure to valproate particularly at $\mathrm{h}$ igh e r do s e can le ad to neurodevelopmental problems in children that may persist even to older age. Some of these issues can lead to practical difficulties with education and social adaptation.

\section{Conclusion :}

Epilepsy is a common neurological problem in the community. It has considerable ramifications in the biological, developmental, and social domains for the affected person and the family. WWE are exposed to these difficulties to a greater extent than men. WWE in the reproductive age have additional health problems related to pregnancy and structural and cognitive development of their children. Exposure to sodium valproate as an antiepileptic drug in pregnancy can lead to increased risk of fetal malformation and cognitive development. Preconception counselling and optimization of treatment of epilepsy is the key to improve the pregnancy outcome for WWE. It is important to highlight the fact that more than 90 per cent of WWE can expect safe pregnancy and healthy babies. All women need to have a systematic antenatal evaluation and screening for fetal malformation. Children of WWE need to be followed up for possible cognitive developmental impairments so that remedial measures could be instituted as soon as required.

\section{REFERENCES :}

1. Reynolds EH (2005). Milestones in the history of epilepsy in Atlas: Epilepsy care in the world WHO, Geneva.

2. Hippocrates. The sacred disease. In: The genuine works of Hippocrates. Birmingham AL. The classics of Medicine Library, Gryphon Editions, 1985.

3. Burneo JG (2003). Sonko-Nanay and epilepsy among the Incas. Epilepsy Behav 4(2):181-184.

4. Jilek-Aall L (1999). Morbus sacer in Africa: some religious aspects of epilepsy in traditional cultures. Epilepsia 40(3):382-386.

5. Sridharan R, Murthy BN (1999). Prevalence and Pattern of epilepsy in India. Epilepsia 40:631-636. 
6. Mani KS, Rangan G, Srinivas HV, Kalyanasundaram S, Narendran S, Reddy AK (1998). The Yelandur study: a community-based approach to epilepsy in rural South India-epidemiological aspects. Seizure 7(4):281-288.

7. Thomas SV, Sarma PS, Alexander M, et al. (2001). Economic burden of epilepsy in India. Epilepsia 42(8):1052-1060.

8. Thomas SV, Nair A (2011). Confronting stigma of epilepsy. Ann Indian Acad Neurol 14:158-163.

9. Radhakrishnan K, Pandian JD, Santhoshkumar T, et al. (2000). Prevalence, knowledge, attitude, and practice of epilepsy in Kerala, South India. Epilepsia 41(8): $1027-$ 1035.

10. Gopinath M, Sarma PS, Thomas SV ( 2011 ). Gender-s pecific psychosocial outcome for women with epilepsy. Epilepsy Behav 20:44-47.

11. Thomas S V, De etha TD, Prabhachandran Nair, Sarma PS (2006). Fewer women receive tertiary care for epilepsy in Kerala State, India. Epileptic Disorders 8:184-189.

12. Thomas SV, Deetha TD, Kurup JR, Reghunath B, Radhakrishnan K, Sarma PS (1999). Pregnancy among women with epilepsy. Ann Indian Acad Neurol 2:123-128.
13. Sukumaran SC, Sarma PS, Thomas SV (2010). Polytherapy increases risk of infertility in women with epilepsy. Neurology 75:1351-1355.

14. Thomas SV, Sarma PS, Nirmala C, Mathai A, Thomas SE, Thomas AC (2013). Women with epilepsy and infertility have different reproductive hormone profile than others. Ann Indian Acad Neurol 16:544-548.

15. Nair SS, Harikrishnan S, Sarma PS, Thomas SV (2016). Metabolic syndrome in young adults with epilepsy. Seizure 37:61-64.

16. Thomas SV, Syam U, Devi JS (2012). Predictors of seizures during pregnancy in women with epilepsy. Epilepsia 53(5):e85-e88.

17. Viale L, Allotey J, Cheong-See F, et al.; for EBM CONNECT Collaboration (2015). Epilepsy in pregnancy and reproductive outcomes: a systematic review and meta-analysis. Lancet 386:18451852.

18. Thomas SV, Sindhu K, Ajaykumar B, Devi PB, Sujamol J (2009). Maternal and obstetric outcome of women with epilepsy. Seizure 18:163-166. 
19. Tomson T, Battino D, Bonizzoni E, et al.; EURAP study group (2011). Dose-dependent risk of malformations with antiepileptic drugs: an analysis of data from the EURAP epilepsy and pregnancy registry. Lanet Neurol 10(7):609617.

20. Thomas SV, Ajaykumar B, Sindhu K, Nair MK, George B, Sarma PS (2008). Motor and mental development of infants exposed to antiepileptic drugs in utero. Epilepsy Behav 13(1):229-236.

21. Thomas SV, Sukumaran S, Lukose N, George A, Sarma PS (2007). Intellectual and language functions in children of mothers with epilepsy. Epilepsia 48:2234-2240.

22. Gopinath N, Muneer AK, Unnikrishnan S, Varma RP, Thomas SV (2015). Children (10-12 years age) of women with epilepsy have lower intelligence, attention and memory: Observations from a prospective cohort case control study. Epilepsy Res 117:58-62.

23. Bromley RL, Calderbank R, Cheyne $\mathrm{CP}$, Rooney C, Trayner P, ClaytonSmith J,García-Fiñana $\mathrm{M}$, Irwin $\mathrm{B}$, Morrow JI, Shallcross R, Baker GA; UK Epilepsy and Pregnancy Register (2016). Cognition in school-age children exposed to levetiracetam, topiramate, or sodium valproate. Neurology Aug 31.pii: $10.1212 / \mathrm{WNL}$. 0000000000003157. PubMed PMID: 27581218.

24. Meador KJ, Baker GA, Browning $\mathrm{N}$, et al.; NEAD Study Group (2009). Cognitive function at 3 years of age after fetal exposure to antiepileptic drugs. NEJM 360(16):1597-1605.

25. Meador KJ, Baker GA, Browning $\mathrm{N}$, et al.; NEAD Study Group (2011). Foetal antiepileptic drug exposure and verbal versus nonverbal abilities at three years of age. Brain 134(Pt 2):396-404.

26. Meador KJ, Baker GA, Browning $\mathrm{N}$, et al.; NEAD Study Group (2013). Fetal antiepileptic drug exposure and cognitive outcomes at age 6 years (NEAD study): a prospective observational study. Lancet Neurol 12(3):244-252.

27. Adab N, Jacoby A, Smith D, Chadwick D (2001). Additional educational needs in children born to mothers with epilepsy. $J$ Neurol Neurosurg Psychiatry 70(1):15-21. 